\title{
Policy options for improved integration of domestic timber markets under the voluntary partnership agreement (VPA) regime in the Democratic Republic of the Congo
}

Guillaume Lescuyer, Paolo Omar Cerutti, Pitchou Tshimpanga, François Biloko, Bernard Adebu-Abdala, Raphaël Tsanga, Régis Ismael Yembe-Yembe and Edouard Essiane-Mendoula

\section{Key points}

- The Forest Law Enforcement, Governance and Trade (FLEGT) Action Plan, launched in 2003, is the European Union's (EU) response to the global fight against illegal logging. In particular, FLEGT aims at reducing trade in illegal timber between the EU and timber producer partner countries.

- FLEGT operates through two major instruments: bilateral trade agreements — known as voluntary partnership agreements (VPAs) — that are signed with willing producer countries, and the European Union Timber Regulation (EUTR), which came into force in March 2013. The EUTR mandates EU importers to exert due diligence in their sourcing of timber from abroad to exclude illegal supplies.

- To date, six countries have signed VPAs. Among them, five have committed to apply VPA provisions regarding legality verification not only to timber imported to Europe, but also to timber traded on the domestic market in signatory producer countries. This means that timber harvested and traded on the domestic market will be regulated by national VPA licensing schemes (the so-called Timber Legality Assurance System, [TLAS]).

- In 2010, the Democratic Republic of the Congo (DRC) started discussions with the EU to sign a VPA, which, in the current state of negotiations, should cover timber produced by artisanal loggers for the domestic market.

- In recent years, artisanal logging in the has received a lot of negative media and political attention because of the use of smallscale logging permits by industrial companies. This use is proscribed by law and should not be considered representative of the 'real' artisanal and domestic timber sector. In fact, across DRC, artisanal logging remains an individual activity practiced by about 25,000 people with basic equipment.

- Pro-Formal findings indicate that the production of artisanal sawnwood has doubled in DRC over the last 2 decades. It amounts to more than 1 million $\mathrm{m3}, 85 \%$ of which feeds domestic demand. About 112,000 $\mathrm{m}^{3}$ are exported to neighboring countries, especially to Angola and Uganda. If production of sawn wood is converted into roundwood equivalents (RWE), current harvesting is 13 times greater than formal, industrial timber production.

- The timber markets of Kinshasa and of eastern DRC generate a turnover exceeding USD 100 million per year, with a USD 25 million profit (excluding profits from indirect activities). Local populations are major beneficiaries of chain-saw milling: they derive an estimated income of around USD 50 million per year from the sale of trees, wages, profits and formal payments by chain-saw millers.

- At the national scale, the average profit rate fluctuates in the range of USD $15-33 / \mathrm{m}^{3}$, while the overall operating cost is USD $150-200 / \mathrm{m}^{3}$. In the provinces of Bas Congo (where artisanal logging is banned) and Bandundu chain-saw milling is especially lucrative for individual operators. Surprisingly, in the eastern part of the country, permit holders hardly earn any income from their activities, due to the expense of small-scale logging permits and dependence on employers who tend to keep them indebted.

- The average size of trees harvested is relatively large, with a timber volume per tree of $10-17 \mathrm{~m}^{3}$. The focus of chain-saw millers on large trees indicates that they are still available in the study areas and the younger and smaller trees are not yet cut. Similarly, the small number of species that are harvested by chain-saw millers does not seem to represent a threat to the integrity of the forest, even though this contributes to a decrease in its economic value.

- Four approaches can be considered to better regulate and sustain chain-saw milling in DRC: (1) a range of practical measures can change problematic behaviors of some key players in the short-term; (2) commercial, technical, financial and institutional support may be provided to legal artisanal sawyers; (3) legal timber should be promoted through public procurement policies; and (4) reform of the legal framework is necessary for better regulation of the chain-saw milling sector in the long-term.

\section{Background}

DRC has more than 125 million ha of forests, covering almost 60\% of the national territory. Although half of this area is considered potentially exploitable for timber production, the area officially assigned to logging is limited to 10 million ha. Available data on forest cover change indicates a net annual deforestation rate of approximately $0.2 \%$ in $1990-2000$ and around $1 \%$ for primary forests in 2000-2010 (Zhuravleva et al. 2013). Small-scale farming and artisanal timber exploitation are considered the main drivers of deforestation and forest degradation.

The quantitative and qualitative findings of Pro-Formal indicate that the internal and regional consumption of timber harvested by Congolese nationals with artisanal means such as chain saws is far greater than large-scale industrial production (Table 1). The sector also contributes substantial revenues to rural economies (Lescuyer et al. 2014). 
The Forest Code of 2002 updated the Congolese forest regime that dated from a 1949 colonial decree. "The forestry regime aims to promote rational and sustainable management of forest resources to increase their contribution to economic, social and cultural development of present generations while preserving forest ecosystems and biodiversity for future generations" (Article 2, Democratic Republic of the Congo 2002). The Forest Code (1) generalizes the requirement of forest inventory and management, (2) introduces the principle of tendering in the allocation of timber concessions, (3) provides for the establishment of forest advisory councils at national and provincial levels, (4) sets a special tax with an obligation to grant a portion of the amount to a national forest fund, and (5) introduces the possibility for local communities to be granted forest concessions. However, implementation decrees for these prescriptions are still awaited, which reduces the practical application of the code. In addition, a new law on nature conservation is being developed.

DRC and the EU started official VPA negotiations in October 2010, after an official request issued by DRC in February that year. On both occasions, the domestic timber market and chain-saw milling received special mentions as relevant topics to be tackled during negotiations, which are ongoing. The current version of the legality matrix (proposed by DRC's Technical Commission) is organized according to six principles, with criteria and indicators.

As in several neighboring countries, the law lists a single permit (Permis de Coupe Artisanale, PCA) that can be used by chain-saw millers to legally harvest timber. These permits must be granted only to individual Congolese nationals who serve the domestic timber market. In recent years, in two provinces, they have instead

\section{Table 1. Major quantitative findings - Democratic Republic of the Congo}

\begin{tabular}{lr}
\hline Consumption or export locations & m $^{3} /$ year \\
\hline Kinshasa - artisanal & 174,619 \\
Kinshasa - industrial & 61,353 \\
Kisangani & 58,207 \\
Sampled major cities in eastern DRC (Beni, Bunia, & 109,922 \\
Goma, Butembo, Aru) & \\
Kindu - Maniema & 8,750 \\
Other cities of DRC & 560,195 \\
Export to Uganda & 59,423 \\
Export to Rwanda & 5,616 \\
Export to Angola & 47,000 \\
Total artisanal consumption & $1,023,732$ \\
Total artisanal consumption (RWE) & $3,071,197$
\end{tabular}

Official industrial exports, 2011

Official production (all products, RWE, 2011) been granted to non-national, medium- to large-scale logging companies who serve the international market, as documented by several national and international nongovernmental organizations, including Greenpeace and Global Witness.

Apart from such illegal use, Pro-Formal results indicate that artisanal exploitation permits are infrequently requested by, delivered to, and used by, chain-saw loggers in DRC. As could be expected in such a vast country as DRC, however, different local contexts exist. In Bas Congo Province, chain-saw milling has been suspended for several years, so no legal permits are available. The measure does not seem to be effective, as results show that about 32\% of timber sold on the markets in Kinshasa is sourced from Bas Congo Province. Harvesting without permits can also be observed around Bandundu, though no ban is in place there. Conversely, in Orientale Province, results indicate that about 52\% of interviewed chain-saw millers did own a 'permit' (i.e. a piece of paper indicating that authority had been granted by someone to harvest timber in a certain area). However, these permits resemble (at least in their denomination and format) the official ones only in $36 \%$ of cases, and even on such occasions official chain-saw millers frequently go beyond the temporal and spatial boundaries of their permits.

Overall, results suggest three main issues that should be discussed during VPA negotiations: (1) the need to clarify and streamline procedures of delivery, to stop the current overlapping of several authorities delivering PCAs, without the law granting them such authority; (2) decentralization of authority for the granting of permits, together with control and verification, to the administrative service that is closest to the operators (Services de I'Environnement); (3), revoking the suspension of chain-saw milling in Bas Congo Province and delivering permits that are based on sound considerations about the scarcity of the resource there. Regarding the decentralization of authority for granting permits, provincial governments could also be suitable for such a role; however, they are unlikely to have the capacity to meet the real needs of chain-saw millers, because of the vast area of individual provinces and poor communication channels within them. Decentralizing authority to the Services de l'Environnement could be a short- to medium-term solution, in view of a better inclusion of chain-saw milling in discussions held at the provincial or even central level, but one that seems to be unavoidable if a realistic roadmap for VPA implementation is to be envisaged.

\section{Policy options}

Problem. Contradictions, incoherencies and gaps in several legal texts leave a door open to illegal harvesting and trade.

\section{Recommendations}

- Repeal Article 11 of Arrêté 011 of 12 April 2009 and maintain Arrêté 035 as the only valid text regulating chain-saw milling, in order to resolve the conflict of authority currently existing between national and provincial authorities to issue permits.

- $\quad$ Once the legal framework is clarified, consider decentralizing the granting, control and verification of PCAs to the provincial Services de l'Environnement, which are the closest administrative service to the operators. National or provincial authorities could still maintain the role of supervision and control.

- Draft an implementing decree for Article 25 of Arrêté 035, to establish the fee to be paid to obtain a PCA. Adopt a medium-term communication strategy to disseminate this 


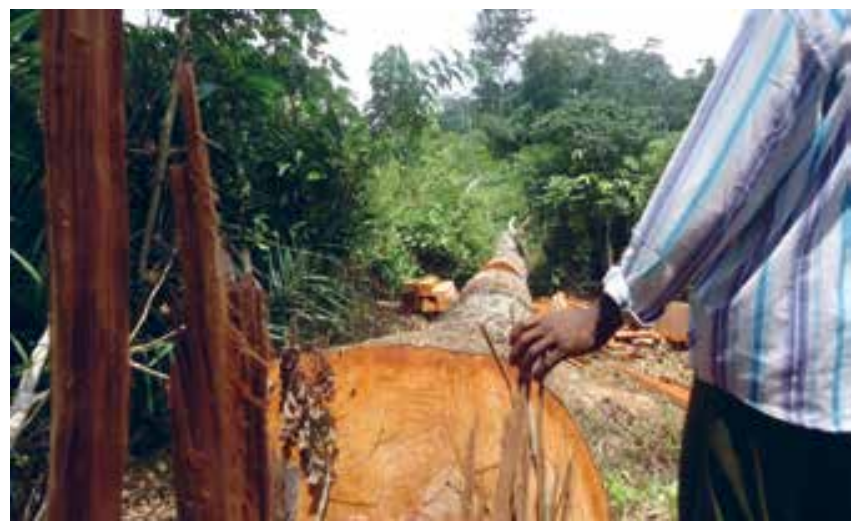

Harvesting operations, DRC.

Photo by Francois Biloko, Reseau CREF, Goma, DRC

decree to the provinces, in local languages, so that operators are aware of the fee to be paid for a PCA.

Problem. The community forests (forêts des communautés locales, FCL) could be a (legal) partial response to the domestic timber needs, but for that to happen several legal texts and regulations must be adopted.

\section{Recommendations}

- $\quad$ Revise Article 71 of the Forest Code (establishing a single model of management plan for all forestry activities) and introduce a simplified model of management plan for $\mathrm{FCL}$, with details about how harvesting should occur and with which types of machinery.

- Management rules must also be established simultaneously for chain-saw milling. A PCA cannot cover an area larger than 50 ha, and it is not realistic to require a management plan similar to that for a logging concession. Findings indicate two options: (1) adopting a simplified model of management plan (simpler than the one for $\mathrm{FCL}$ ), or (2) modifying the PCAs so that they are not based on maximum areas but on harvestable volumes (over a given period of time). The second option would be easier to apply to the current method of operation of chainsaw loggers, who are highly mobile and follow market demand and availability of timber species. Moreover, the second option (based on volumes of trees) could facilitate increased benefits for the customary owners of trees, because negotiations would occur between them and operators, bypassing the current ones between operators and village chiefs. These chiefs consider themselves to be the customary owners, thus requesting payments be made to them.

Problem. The aim of the Forest Code is to create a class of national operators in the forestry sector. The PCA responds to this aim, but its current legal constraints (e.g. Article 23 of Arrêté 035 listing which types of saws could be used) do not permit the emergence of such class.

\section{Recommendations}

- $\quad$ Revise Article 23 and allow PCA owners to use mobile saws that could greatly improve the quality of the final product and the ease of operations.

- Whether PCAs are maintained on the current area-based model or they are changed to a volume-based one, consider increasing the authorized areas (results indicate an area of 300-1,000 ha/year could better promote the emergence of such a class of operators) or volumes.

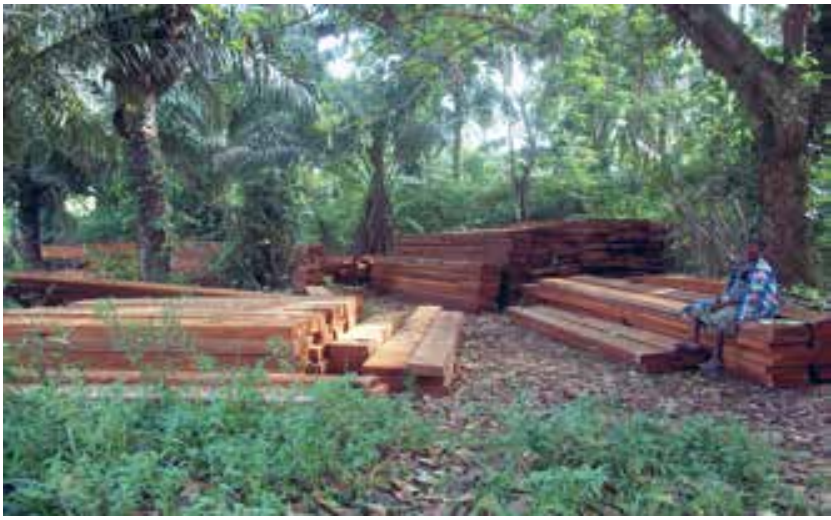

Sawn wood ready for transport, DRC.

Photo by Francois Biloko, Reseau CREF, Goma, DRC

- Allow an extension of the PCA period of validity (e.g. 1 year, renewable once)

Problem. The difference of context between provinces and their varied legal frameworks prevents the homogeneous enforcement of the Forest Code regarding chain-saw milling.

\section{Recommendation}

- $\quad$ Establish different (possibly provincial) schedules for implementation of the revised legal framework, notably those regulations concerning chain-saw milling. Implementing a single agenda over the entire national territory would probably not be as effective as adopting a decentralized approach to implementation.

Problem. Chain-saw millers pay a panoply of informal 'taxes', most of them not included in Article 121 of the Forest Code. Also, in many cases, the legally established taxes are paid but no receipt is provided to chain-saw millers. This questions the destination of such payments (estimated at about USD 10 million a year for Orientale Province and around Kinshasa).

\section{Recommendations}

- $\quad$ One of the major points of agreement among all participants in the national workshops held in DRC was the establishment of one single point where all relevant taxes related to the PCA must be paid.

- For a period of at least 3 years, print and distribute to all grantees of PCA and other relevant actors a leaflet with all the official taxes that must be paid for their timber to be legal.

Problem. Relations between chain-saw millers and the rural population are often conflicted, and most of the (financial or in kind) benefits remain with the local chiefs. Several forms of 'contractual agreements' (cahiers des charges) between chain-saw loggers and the local population (represented by the chief) already exist. Results indicate that chain-saw millers make payments of about USD 2000 per operation, but experience a lot of recrimination from the local population about both the amounts disbursed and the use made of such money (generally retained by the chief).

\section{Recommendation}

- Adopt a standard official template for the contractual agreements to be used when PCAs are granted, to be signed by representatives of each lineage in the village and the chain-saw millers. The template should also include a section 
specifically indicating what will be the final use of the money collected, in order to reach more equitable benefit-sharing.

Problem. There is little demand for 'legal' timber on the domestic market. After more than a decade of increasing informal activities, with concomitant growth in corrupt practices among State officials in the timber value chain, operators are not very interested in the legal status of timber - especially if producing 'legal' timber results in more 'taxes' for them and higher prices for the final consumers.

\section{Recommendations}

- On the demand side, the constraint is largely physical. At present, no means exists to differentiate timber produced with a valid permit from timber produced informally. Other countries (notably Cameroon) are opting for the creation of so-called 'clusters' of timber sellers (in large cities), i.e. physical markets where only timber produced with valid permits can be accepted and sold. This approach could be replicated in Kinshasa or Kisangani, for instance, where 'specialization' already exists, for instance in several markets that only sell industrial scraps. Traceability, even for responsible sellers, however, will remain a problem until the legal framework and an initial TLAS become operational.

- As in all other Pro-Formal countries, we believe public procurement policies could create at least the initial conditions for a legal market to be initiated in large cities, with operators specializing in procurement of legal timber for public works (funded not only by the government but also with official development assistance).

- $\quad$ Results indicate that domestic market prices for timber in Kinshasa are close to international timber prices (20\% cheaper, as compared for instance with an average in Cameroon of $80 \%$ cheaper). This situation could be used to test on a pilot scale an alternative option for industrial companies, which could be provided with a few incentives (e.g. 0\% VAT on timber sold locally) if they decide to sell on the domestic timber market.

\section{References}

[DRC] Democratic Republic of the Congo. 2002. Loi n.011/2002 du 29 août 2002 portant Code forestier. Kinshasa, Democratic Republic of the Congo.

Lescuyer G, Cerutti PO, Tshimpanga P, Biloko F, Adebu-Abdala B, Tsanga R, Yembe-Yembe Rl and Essiane-Mendoula E. 2014. The domestic market for small-scale chainsaw milling in the Democratic Republic of Congo: Present situation, opportunities and challenges. Occasional Paper 112. Bogor, Indonesia: Center for International Forestry Research. [French version also available: Lescuyer G, Cerutti PO, Tshimpanga PC, Biloko F, Adebu Abdala $B$, Tsanga R, Yembe RI and Essiane Mendoula E. 2014. Le marché domestique du sciage artisanal en République démocratique du Congo: Etat des lieux, opportunités, défis. Occasional Paper 110. Bogor, Indonesia: Center for International Forestry Research.]

Zhuravleva I, Turubanova S, Potapov P, Hansen M, Tyukavina A, Minnemeyer S, Laporte N, Goetz S, Verbelen F and Thies C. 2013. Satellite-based primary forest degradation assessment in the Democratic Republic of the Congo, 2000-2010. Environmental Research Letters 8(2).

\section{Additional reading}

Kishor N and Lescuyer G. 2012. Controlling illegal logging in domestic and international markets by harnessing multi-level governance opportunities. International Journal of the Commons 6(2):255-70.

Putzel L, Kelly A, Cerutti PO and Artati Y. 2014. Formalization of natural resource access and trade: Insights from land tenure, mining, fisheries, and non-timber forest products. Bogor, Indonesia: Center for International Forestry Research.

Wit M, van Dam J, Cerutti PO, Lescuyer G, Kerrett R and Parker Mckeon J. 2011. Chainsaw milling: Supplier to local markets - A synthesis. In Wit M and van Dam J, eds. Chainsaw milling: Supplier to local markets. Wageningen, the Netherlands: Tropenbos International. VII-XXII.

The EU-funded project Pro-Formal (EuropeAid/ENV/2010-242904/TPS) was implemented by the Center for International Forestry Research (CIFOR) in three regions (Southeast Asia, sub-Saharan Africa and Latin America) and five countries (Indonesia, Cameroon, the Democratic Republic of the Congo, Ecuador and Gabon from July 2010 to December 2013. The project has been implemented with several key partners, and some outputs have already been disseminated through CIFOR's occasional papers, infobriefs, scientific journal articles and other web-based materials (available on the project website: www.cifor.org/pro-formal).

\begin{tabular}{|c|c|c|}
\hline CGIAR & $\begin{array}{l}\text { RESEARCH } \\
\text { PROGRAM ON } \\
\text { Forests, Trees and } \\
\text { Agroforestry }\end{array}$ & $\begin{array}{l}\text { This research was carried out by CIFOR as part of the CGIAR Research Program on Forests, Trees and } \\
\text { Agroforestry (CRP-FTA). This collaborative program aims to enhance the management and use of } \\
\text { forests, agroforestry and tree genetic resources across the landscape from forests to farms. CIFOR } \\
\text { leads CRP-FTA in partnership with Bioversity International, CATIE, CIRAD, the International Center for } \\
\text { Tropical Agriculture and the World Agroforestry Centre. }\end{array}$ \\
\hline
\end{tabular}
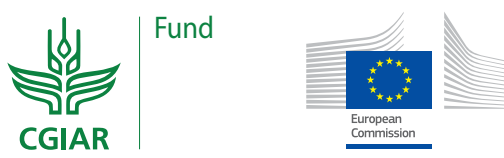